\title{
Activation of Prefrontal Cortical Parvalbumin Interneurons Facilitates Extinction of Reward-Seeking Behavior
}

\author{
Dennis R. Sparta, ${ }^{1,2}$ Nanna Hovelsø,${ }^{1,4,5}$ Alex 0. Mason, ${ }^{1}$ Pranish A. Kantak, ${ }^{1}$ Randall L. Ung, ${ }^{1,3}$ Heather K. Decot, ${ }^{1,3}$ \\ and Garret D. Stuber ${ }^{1,2,3}$ \\ ${ }^{1}$ Departments of Psychiatry and Cell Biology and Physiology, University of North Carolina Neuroscience Center, ${ }^{2}$ Bowles Center for Alcohol Studies, and \\ ${ }^{3}$ Curriculum in Neurobiology, University of North Carolina at Chapel Hill, Chapel Hill, North Carolina 27599; ${ }^{4}$ Synaptic Transmission 1, Neuroscience Drug \\ Discovery Denmark, Lundbeck, Copendhagen-Valby, Denmark 2500; and ${ }^{5}$ Department of Neuroscience and Pharmacology, Faculty of Health Sciences, \\ University of Copenhagen, Copenhagen, Denmark 2200
}

Forming and breaking associations between emotionally salient environmental stimuli and rewarding or aversive outcomes is an essential component of learned adaptive behavior. Importantly, when cue-reward contingencies degrade, animals must exhibit behavioral flexibility to extinguish prior learned associations. Understanding the specific neural circuit mechanisms that operate during the formation and extinction of conditioned behaviors is critical because dysregulation of these neural processes is hypothesized to underlie many of the maladaptive and pathological behaviors observed in various neuropsychiatric disorders in humans. The medial prefrontal cortex (mPFC) participates in the behavioral adaptations seen in both appetitive and aversive-cue-mediated responding, but the precise cell types and circuit mechanisms sufficient for driving these complex behavioral states remain largely unspecified. Here, we recorded and manipulated the activity of parvalbumin-positive fast spiking interneurons (PV+ FSIs) in the prelimbic area ( $\mathrm{PrL})$ of the $\mathrm{mPFC}$ in mice. In vivo photostimulation of $\mathrm{PV}+$ FSIs resulted in a net inhibition of PrL neurons, providing a circuit blueprint for behavioral manipulations. Photostimulation of mPFC PV + cells did not alter anticipatory or consummatory licking behavior during reinforced training sessions. However, optical activation of these inhibitory interneurons to cues associated with reward significantly accelerated the extinction of behavior during non-reinforced test sessions. These data suggest that suppression of excitatory mPFC networks via increased activity of PV + FSIs may enhance reward-related behavioral flexibility.

\section{Introduction}

The medial prefrontal cortex ( $\mathrm{mPFC}$ ) is a critical neural substrate for the expression and extinction of cue-mediated behaviors in rodents in both the appetitive and aversive domains (Kalivas et al., 2006; Quirk and Mueller, 2008; Peters et al., 2009; SotresBayon and Quirk, 2010; Van den Oever et al., 2010; Van den Oever et al., 2013). The mPFC can be subdivided into several subnuclei based on neuroanatomy and projection targets. The prelimbic (PrL), infralimbic (IL), and anterior cingulate cortex (ACC) are key modulators of subcortical regions, including the amygdala and nucleus accumbens, that mediate cue-driven motivated behaviors (Vertes, 2004; Gabbott et al., 2005; Gutman et al., 2012). Electrophysiological and immunohistochemical stud-

\footnotetext{
Received Jan. 17, 2013; revised Jan. 24, 2014; accepted Jan. 27, 2014.

Author contributions: D.S., N.H., A.M., and G.D.S. designed research; D.S., N.H., A.M., P.K., and H.D. performed research; D.S., N.H., A.M., R.U., H.D., and G.D.S. analyzed data; D.S., A.M., and G.D.S. wrote the paper.

This study was supported by the National Alliance for Research on Schizophrenia and Depression, the Alcoholic Beverage Medical Research Foundation, The Whitehall Foundation, The Foundation of Hope, the National Institutes of Health-National Institute on Alcohol Abuse and Alcoholism (Grants AA021417, AA011605, and AA007573), and the National Institute on Drug Abuse (Grants DA029325 and DA032750). We thank the UNC Neuroscience Center Microscopy Facility (supported by NIH Grant P30 NS045892), members of the Stuber laboratory for discussion, Karl Deisseroth for constructs, and the UNC vector core facility for viral packaging.

Correspondence should be addressed to Garret D. Stuber, PhD, Assistant Professor, Departments of Psychiatry and Cell Biology and Physiology, UNC Neuroscience Center, CB 7250, University of North Carolina at Chapel Hill, Chapel Hill, NC 27599. E-mail: gstuber@med.unc.edu.

DOI:10.1523/JNEUROSCI.0235-13.2014

Copyright $\odot 2014$ the authors $\quad 0270-6474 / 14 / 343699-07 \$ 15.00 / 0$
}

ies of mPFC circuitry after fear or appetitive conditioning revealed altered PrL and IL activity at various stages of the acquisition, expression, or extinction of these behaviors (Kalivas et al., 2006; LaLumiere and Kalivas, 2008; Ovari and Leri, 2008; Peters et al., 2008; Rogers et al., 2008; Santini et al., 2008; BurgosRobles et al., 2009; Peters et al., 2009; Hayton et al., 2011). Although it is evident that the mPFC modulates the expression and extinction of cue-mediated behaviors, the role of genetically and functionally defined neuronal subtypes that participate in $\mathrm{mPFC}$ microcircuits remains undefined.

Anatomically, the mPFC is organized into delineated layers that comprise a heterogeneous mixture of cell types with distinct electrophysiological, morphological, and neurochemical properties (Freund, 2003; Markram et al., 2004; Van De Werd et al., 2010). A principal functional dichotomy exists between excitatory pyramidal projection neurons and several classes of inhibitory interneurons with specialized processing roles, including gating excitatory inputs and modulating pyramidal output to other cortical layers and downstream structures (Markram et al., 2004; Vogels and Abbott, 2009). The parvalbumin-positive fastspiking interneurons (PV+ FSIs) have elicited interest for their role in orchestrating cortical oscillations, maintaining excitation/ inhibition balance, and mediating a variety of cognitive behaviors (Uhlhaas and Singer, 2010; Isaacson and Scanziani, 2011; Marín, 2012). Interestingly, optical inhibition of mPFC PV + FSIs induced fear expression in mice, indicating a substantial role for 
these neurons in driving behavioral responses (Courtin et al., 2014). The disruption of these important functions, which is at least partially modulated by PV + FSI activity, may underlie specific behavioral deficits such as cognitive inflexibility observed in many neuropsychiatric disorders (Cardin et al., 2009; Sohal et al., 2009; Yizhar et al., 2011). Despite intense investigation of cortical FSI function, and the importance of the mPFC in controlling behavioral flexibility, the effects of FSI-mediated cortical inhibition on cue-reward associations are unknown. Therefore, we applied optogenetic manipulations in combination with in vivo electrophysiology and behavioral tasks to investigate the net effect of PV+ FSI-mediated inhibition within the mPFC on the processing of learned cues that motivate responding for natural rewards. Specifically, we targeted FSIs within the mPFC with ChR2 using genetic and viral strategies to enable selective optical control of these neurons. We then explored how selective inhibition of $\mathrm{mPFC}$ network activity mediated by optogenetic stimulation of PV + FSIs time locked to salient reward-predictive cue presentation altered cue-mediated behavioral responding and extinction.

\section{Materials and Methods}

Experimental subjects. Adult ( $\geq 22$ g) male mice (hemizygous parvalbumin-Cre for targeting GABAergic interneurons neurons (B6; 129P2-Pvalbtm1(cre)Arbr/J, stock number 008069; The Jackson Laboratory) were used as subjects. All mice were group housed with littermates before surgical procedures, after which all subjects were singly housed. Mice were maintained on a 12:12 light cycle (lights on at 19:00) and given ad libitum food and water access before behavioral training. All mice used in behavioral experiments were mildly food restricted to $\sim 85-90 \%$ of their free-feeding body weight. All experiments were conducted in accordance with guidelines of the University of North Carolina Animal Care and Use Committee.

Stereotaxic recombinant adeno-associated virus injection. Mice were anesthetized with ketamine ( $100 \mathrm{mg} / \mathrm{kg}$, i.p.) and xylazine $(10 \mathrm{mg} / \mathrm{kg}$, i.p) and placed in a stereotaxic frame (Kopf Instruments). Microinjection needles were inserted above the prelimbic mPFC (coordinates from bregma: $+1.85 \mathrm{AP}, \pm 0.5 \mathrm{ML},-2.0 \mathrm{DV})$. Each $\mathrm{mPFC}$ was injected with $0.3-$ $0.5 \mu \mathrm{l}$ of purified and concentrated adeno-associated virus (AAV, $\sim 10^{12}$ infectious units $/ \mathrm{ml}$, serotype 5) to express ChR2 fused to eYFP in a credependent fashion [AAV-EF1 $\alpha$-DIO-ChR2(H134R)-eYFP; Tsai et al., 2009] or only eYFP (AAV-EF1 $\alpha$-DIO-eYFP) as a control group over 5 min, followed by 5 min to allow diffusion of viral particles away from the injection site. For all in vivo behavioral experiments, an optical fiber was implanted above the PrL unilaterally (coordinates from bregma: +1.85 , $\pm 0.5 \mathrm{ML},-1.8 \mathrm{DV}$ ). Mice were allowed at least 2 weeks to recover before behavioral training.

Patch-clamp electrophysiology. Brain slice preparation and general methods for patch-clamp electrophysiology were conducted as described previously (Stamatakis and Stuber, 2012; van Zessen et al., 2012; Jennings et al., 2013). To examine mPFC postsynaptic currents evoked by optical stimulation of $\mathrm{PV}+$ neurons, $200 \mu \mathrm{m}$ coronal slices containing the $\mathrm{mPFC}$ were prepared from mice expressing ChR2-eYFP in $\mathrm{PV}+$ neurons. For whole-cell voltage-clamp recordings, IPSCs from mPFC putative pyramidal neurons, electrodes (2-4 M $\Omega$ electrode resistance) contained the following (in $\mathrm{mm}$ ): 130 cesium chloride, 10 HEPES, 1 EGTA, 2 Mg-ATP, 0.2 Na-GTP, pH 7.2-7.4, 275-285 mOsm. Photostimulation (5 ms pulses of $1-2 \mathrm{~mW}, 473 \mathrm{~nm}$ light delivery via LED through a $40 \times$ microscope objective) was used to stimulate PV+ neurons expressing ChR2-eYFP. All cells were held at $-70 \mathrm{mV}$. The electrode also contained Alexa Fluor 594 to fill the cell for post hoc identification of the location of recorded neurons throughout the mPFC.

In vivo electrophysiology. Parv-ires-cre mice $(n=5)$ were injected with AAV-DIO-ChR2-eYFP, and unilaterally implanted with a 16 microwire $(4 \times 4,35 \mu \mathrm{m}$ tungsten wires, $150 \mu \mathrm{m}$ wire spacing, $150 \mu \mathrm{m}$ row space, $3.55 \mathrm{~mm}$ wire length) microelectrode arrays (MEAs; Innovative Neurophysiology) in the $\mathrm{mPFC}$ for chronic neural recording. Before implanta- tion, electrode arrays were interfaced to a $200 \mu \mathrm{m}$ optical fiber for light delivery to tissue surrounding MEA tips (Sparta et al., 2012). Mice recovered from surgery for $>21 \mathrm{~d}$ before experimentation. For recordings, the MEA was attached to a 16-channel head stage, preamplified, and passed to a 32-multichannel acquisition processor providing a total amplification of $5 \mathrm{~K}$, filtered with bandwidth $500-5 \mathrm{kHz}$, and digitized before being recorded to a PC. Detected waveforms that crossed a threshold based on noise were time stamped and later sorted offline. Discrimination of individual units was performed offline by Offline Sorter (Plexon Instruments) using principal component analysis of waveform shape after removal of artifacts. Units in which $>1 \%$ of interspike intervals were shorter than $2 \mathrm{~ms}$ were excluded from further analysis and all sorted units on the same electrode were subjected to autocorrelational and crosscorrelational analysis to avoid overlap between separately sorted units. Sorted waveforms were further processed in NeuroExplorer to extract unit and optical stimulation timestamp events. NeuroExplorerextracted time stamps were exported to MATLAB and analyzed for statistical significance using the nonparametric Wilcoxon signed-rank test and $z$-scores. Phasic firing responses were deemed statistically significant if any $100 \mathrm{~ms}$ bins in the response window $(0-0.5 \mathrm{~s}$ after cue onset) were statistically significant relative to a $0.5 \mathrm{~s}$ baseline epoch.

Pavlovian conditioning. Parv-ires-cre mice were injected with either AAV-DIO-ChR2-eYFP $(n=13)$ or AAV-DIO-eYFP $(n=13)$ and implanted with an optical fiber terminating immediately above the PrL. Two weeks later, mice underwent $\sim 3 \mathrm{~d}$ of food restriction before starting training on a modified Pavlovian conditioning paradigm in which a compound cue light and tone conditioned stimulus (CS) presentation (5 s) preceded and terminated with the delivery of $20 \mu \mathrm{l}$ of a $15 \%$ sucrose solution (adapted from van Zessen et al., 2012). All training sessions comprised 60 CS presentations that were delivered in a randomized 60 $120 \mathrm{~s}$ intertrial interval. All mice were trained for 20-30 sessions to criterion (high anticipatory and reward licking that remained stable $[<10 \%$ variation] across three sessions) before extinction testing began. Implanted optical fibers were interfaced to optical patch cables for at least 10 sessions before any optical stimulation session to habituate the mice to the procedure. Upon reaching stable cued-reward licking behavior, all mice underwent a paired and unpaired stimulation session to examine the effects of PV + FSI excitation on stable reward-related behavioral responding. Paired and unpaired stimulation sessions were identical to training sessions except that mice received $5 \mathrm{~s}$ of time locked optical stimulation to the mPFC to activate $\mathrm{PV}+$ neurons during all cue presentations (Paired) or $\sim 60,5 \mathrm{~s}$ optical stimulations that were randomly delivered unpaired with the cue throughout the session (Unpaired). These controls were conducted to determine whether any change in cuemediated reward behavior during extinction testing was a nonspecific effect of light delivery.

Extinction paradigm. Upon completion of the paired and unpaired photostimulation sessions, all mice underwent additional Pavlovian conditioning sessions until they reached stable cued reward licking behavior ( $<10 \%$ variation for 3 consecutive days). Once stable responding was achieved, all mice underwent an extinction session. The extinction session comprised $200 \mathrm{CS}$ presentations separated by an intertrial interval of 60-120 s. Throughout the extinction experiment, optical stimulations to selectively activate mPFC PV+ FSIs were delivered time locked to the $5 \mathrm{~s}$ CS. In addition, sucrose delivery was omitted after all CS presentations

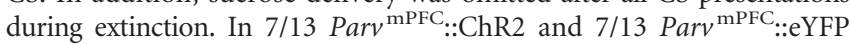
mice, an additional extinction test session was conducted on the next day and laser-light delivery was completely withheld. This was conducted to determine whether PV + neuron activation could influence extinction responding behavior on a subsequent recall session.

Virus expression and histology. After behavioral experiments, mice were deeply anesthetized, perfused transcardially, and brains were collected as described previously (van Zessen et al., 2012). Fluorophore expression (ChR2-eYFP or eYFP) was examined using an epifluorescent microscope and a confocal microscope, with images processed and analyzed using ImageJ. Mice without eYFP expression in the MPFC due to faulty microinjections or mice with optical fibers and MEAs outside of the $\mathrm{mPFC}$ were excluded from analysis. In a subset of mice, parvalbumin was labeled and visualized with incubation in a primary rabbit anti- 
A

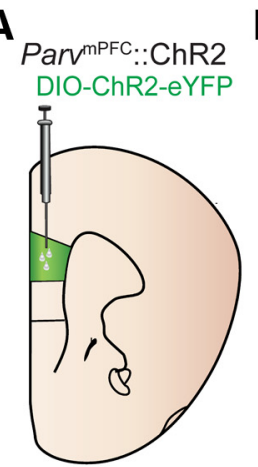

C
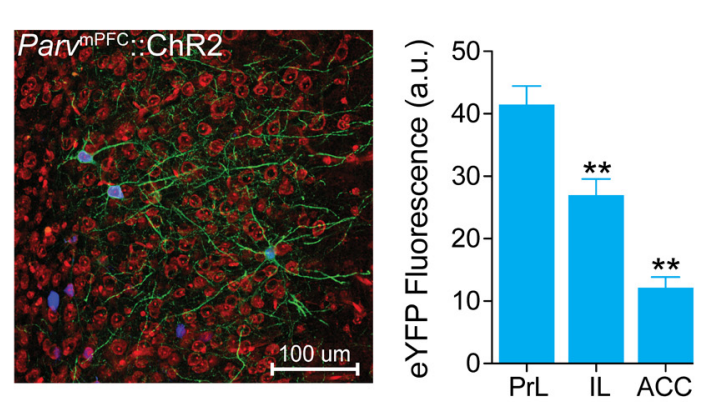

E Patch-clamp slice electrophysiology

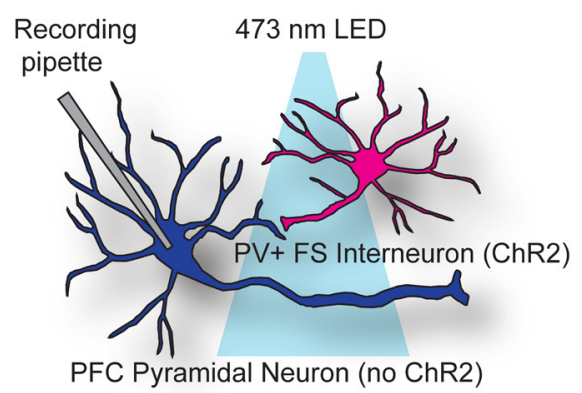

$\mathbf{F}$

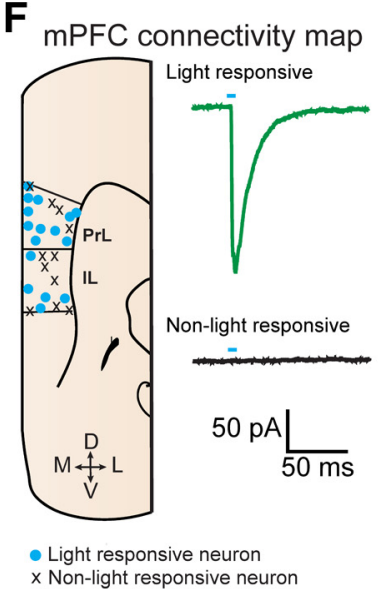

G

Light responsive Non-light responsive

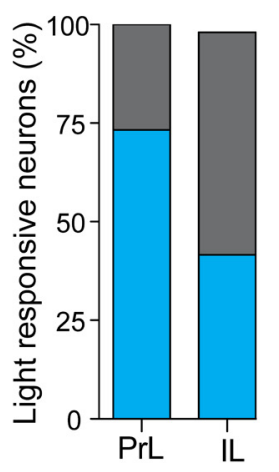

Figure 1. Optogenetic analysis of mPFC neurons. $\boldsymbol{A}$, Schematic depicting viral delivery method of AAV5-DI0-ChR2-eYFP into the MPFC in Parv-ires-cre-mice. $\boldsymbol{B}$, Representative coronal section of the $\mathrm{MPFC}$ with expression of ChR2-eYFP (green) in PV+ interneurons in the PrL and IL region. D, Dorsal; V, ventral; M, medial; L, lateral. Scale bar, $500 \mu \mathrm{m}$. C, Highermagnification confocal image of the PrL mPFC showing PV + interneurons expressing ChR2 that were immunohistochemically labeled for parvalbumin (blue). Neurons colabeled in green and blue are positive for both ChR2 and parvalbumin. Red shows counterstaining with $640 \mathrm{~nm}$ Neurotrace to label all neuronal cell bodies. D, Quantified ChR2-eYFP fluorescence intensity within the $\mathrm{mPFC}$ (two sections from three mice). Fluorescence intensity is significantly greater parvalbumin antibody (1:2000; AbCam) in normal donkey serum in $0.1 \%$ phosphate buffer containing Triton X-100 for 48 h. A Dylight 405 donkey anti-rabbit (1:200; Jackson ImmunoResearch Laboratories) was applied to visualize parvalbumin expression to determine colocalization with eYFP expression.

Data analysis. All values are presented as means \pm SEM. Statistical analysis was assessed using repeated-measures ANOVA or $t$ tests. When statistical significance was achieved, post hoc tests (independent and paired $t$ tests) were conducted to compare group means using $\alpha=0.05$ and calculated with SPSS software (IBM). Nonsignificance (ns) was defined as $p>0.05$ and significance as ${ }^{*} p<0.05$ and ${ }^{* *} p<0.001$.

\section{Results}

\section{Genetic targeting of Parv ${ }^{\mathrm{mPFC}}$ neurons}

We first targeted genetically the expression of ChR2-eYFP or eYFP to PV+ interneurons of the mPFC by injecting creinducible AAV constructs into the mPFC of Parv-cre mice (Fig. $1 A)$. Confocal microscopy revealed robust ChR2-eYFP expression throughout the mPFC (Fig. 1B). In addition, immunohistochemistry confirmed that the majority of transduced neurons expressing ChR2-eYFP also stained positively for parvalbumin (Fig. 1C). Neurons that were identified as expressing eYFP were highly colocalized with parvalbumin $(n=50 / 50$ eYFP-positive mPFC neurons; $n=4$ animals). We also quantified the average expression of eYFP that was targeted to $\mathrm{PV}+$ interneurons throughout the mPFC. We found that eYFP fluorescence was significantly greater in the PrL compared with IL and the ACC (ANOVA: $F_{(2,15)}=35.385, p<0.001$; Fig. $1 D$ ). To examine the functional connectivity between $\mathrm{mPFC}$ PV + FS interneurons and putative pyramidal neurons, whole-cell recordings from putative mPFC pyramidal neurons revealed that photostimulation of ChR2-containing cell bodies and fibers originating from PV+ mPFC neurons produced IPSCs and formed functional synapses on pyramidal neurons within the mPFC (Fig. $1 E-G$ ). In addition, we found that $73.3 \%(11 / 15)$ of pyramidal neurons in the PrL were light responsive compared with only $41.8 \%(5 / 12)$ of pyramidal neurons within the IL (Fig. $1 G$ ). Together, these data suggest that our methods allowed for preferential targeting and manipulation of PrL PV + neurons, with weaker infection and modulation of $\mathrm{PV}+$ neurons in other mPFC subregions.

\section{Photostimulation of $\mathrm{Parv}^{\mathrm{mPFC}}$ neurons in freely moving mice inhibits $\mathrm{mPFC}$ putative pyramidal neurons}

Next, we combined optical activation and multiunit electrode recording (Fig. $2 A$ ) to monitor the single unit activity of mPFC neurons in awake and behaving mice $(n=5$ mice). Spike waveform analysis revealed that neurons classified as putative pyramidal or PV+ FSIs clustered into two groups according to time to peak and half-valley width, supporting our classification based on basal firing rate and change in activity to optical stimulation (Fig. $2 B, C)$. Recorded units displayed 1 of 3 characteristic responses to $5 \mathrm{~s}$ optical stimulations of PV+ FSIs. A subpopulation of neurons displayed high baseline firing rates and a significant increase in firing time locked to optical stimulation (7/37 units), which is

in the PrL compared with other regions of the MPFC. **Significant difference compared with the PrL. E, Schematic diagram depicting combined patch-clamp electrophysiological and optogenetic manipulations in the MPFC. $F$, Left, Location of light-responsive and non-light-responsive pyramidal cells in coronal mPFC slices following photostimulation of Parv ${ }^{\mathrm{mPFC}}$.:ChR2 cell bodies and projections. Right, Example trace of a light-responsive (top) and a non-light-responsive (bottom) $\mathrm{mPFC}$ neuron. G, Percentage of light-responsive versus non-light-responsive neurons in the $\mathrm{mPFC}$ after photostimulation of PV + FSIs. All values for all figures represent mean \pm SEM. ${ }^{*} p<0.05 ;{ }^{* *} p<0.01$. 
A

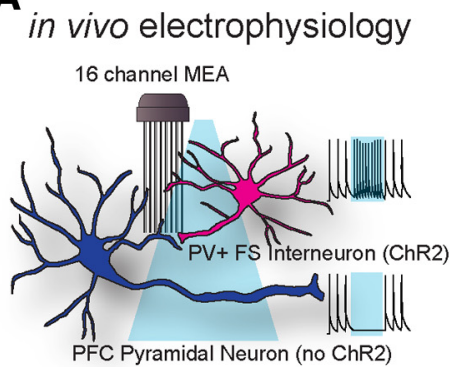

D

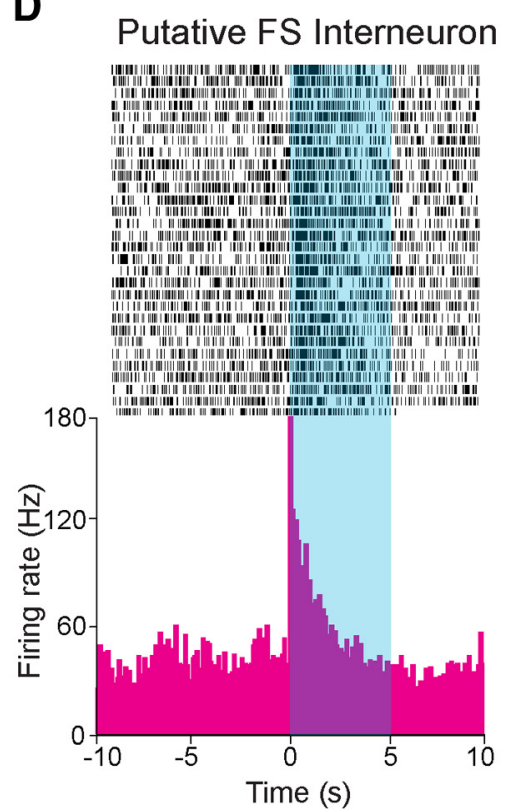

B

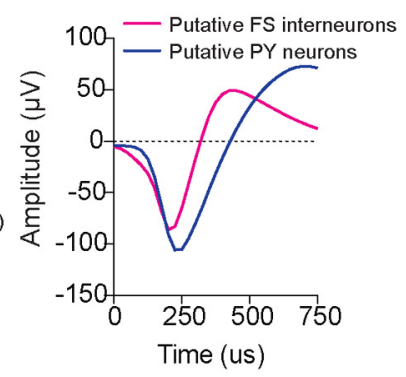

E

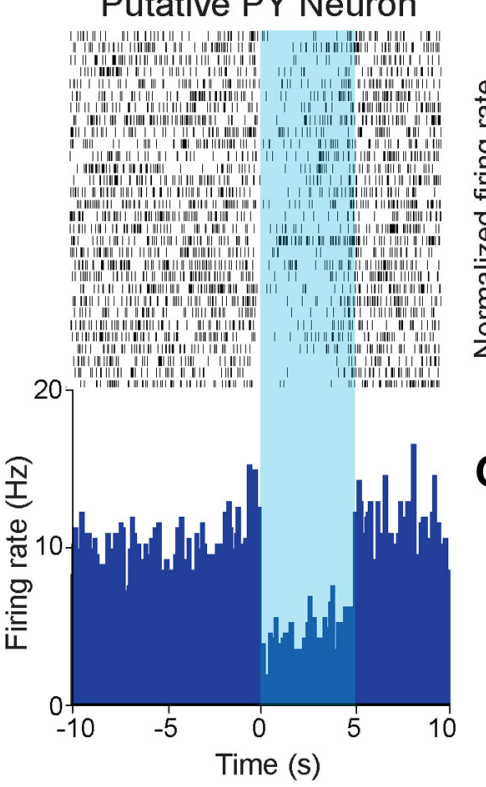

C

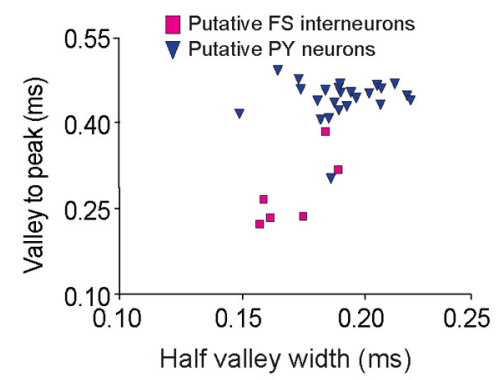

F

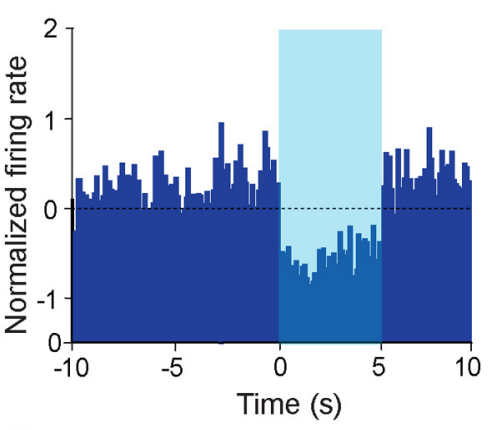

G

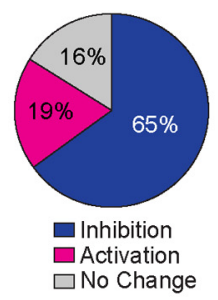

Figure 2. In vivo electrophysiological analysis of mPFC neurons. $\boldsymbol{A}$, Schematic diagram depicting combined in vivo electrophysiological and optogenetic manipulations in the mPFC, with typical change of firing rate in putative pyramidal neurons and putative PV + FSIs in response to blue light stimulation. $\boldsymbol{B}$, Example isolated waveform from an optically identified putative $m P F C$ pyramidal PV + FS interneuron and pyramidal neuron. C, Classification of putative PY and FS interneurons based on the correlation of the electrophysiological parameters, valley to peak duration (ms) and half-valley width (ms). $\boldsymbol{D}, \boldsymbol{E}$, Representative perievent histograms and raster plot of a single unit putative PV+ FSI (D) and pyramidal neuron (PY; $\boldsymbol{E})$ time locked to 5 ms light stimulation. $\boldsymbol{F}$, Normalized change in firing of all recorded putative $\mathrm{mPFC} \mathrm{PY} \mathrm{neurons} \mathrm{(} n=24$ units) in response to optical activation of PV+ FS interneurons. $\mathbf{G}$, Pie chart of three characteristic neural firing responses to optical stimulation and the proportion of all recorded neurons that displayed increased firing (activation), decreased firing (inhibition), or no change ( $n=37$ units).

consistent with the properties of PV+ FSIs (Fig. 2D, G). Another group of neurons responded to blue light stimulation with a significant decrease in their firing rates (24/37 units; Fig. 2E-G). A subset of recorded neurons displayed no change in their firing rate in response to optical stimulation of PV+ FSIs (6/37 units). Therefore, these data demonstrate that transient optogenetic stimulation of PV + FSIs resulted in a time-locked excitation of putative $\mathrm{PV}+$ neurons with a concurrent reduction in firing in the majority of mPFC neurons in freely moving animals.

\section{Photostimulation of Parv ${ }^{\text {mPFC }}$ neurons does not alter cue-mediated licking behavior during a standard Pavlovian training session}

Presentation of reward predictive cues engages distributed neural circuits to promote reward seeking. Therefore, we tested whether activation of mPFC PV + FSIs during cue presentation alters reward-related licking behavior in a nonextinction context. Interestingly, licking behavior was not significantly altered during the cue period in the paired optical stimulation session between the Parv ${ }^{\mathrm{mPFC}}$ ::eYFP and Parv ${ }^{\mathrm{mPFC}}:: \mathrm{ChR} 2$ groups (repeated-measures ANOVA eYFP vs ChR2: $F_{(1,9)}=0.984, p=0.347$; independent $t$ during the cue period: $t_{9}=-1.220, p=0.253$; Fig. $3 B$ ). Next, we examined whether unpaired photostimulation of Parv ${ }^{\mathrm{mPFC}}$ neurons in both the eYFP $(n=5)$ and $\operatorname{ChR} 2(n=6)$ groups could alter reward-related licking in our Pavlovian task. Similar to our previous finding during paired stimulation sessions, unpaired photostimulation of Parv ${ }^{\mathrm{mPFC}}$ did not alter licking behavior during the laser stimulation or cue period between the eYFP and ChR2 groups (repeated-measures ANOVA eYFP vs ChR2: $F_{(1,9)}=0.326, p=$ 0.582; Fig. $3 C$ ). We did observe a modest, but nonsignificant, increase in licking behavior during the laser stimulation period compared with both the prestimulation and poststimulation period in both groups, which we believe is due to Pavlovian stimulus generalization (data not shown). Together, our results show that photostimulation of $\mathrm{mPFC} \mathrm{PV}+$ FSIs does not inherently alter cue-mediated behavior in well trained animals.

\section{Photostimulation of Parv ${ }^{\text {mPFC }}$ neurons facilitates the extinction of cue-reward associations}

To determine whether transient enhancement of mPFC PV + FSI activity could modulate the extinction of cue-reward behavior, we photostimulated Parv ${ }^{\mathrm{mPF}}$ neurons time locked to cue presentations in an extinction session and quantified licking behavior. We found that Parv ${ }^{\text {PFFC }_{\text {: }} \text { ChR2 mice }}(n=13)$ extinguished 
A

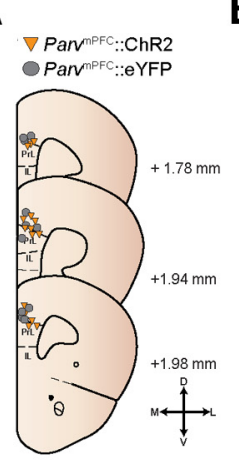

B
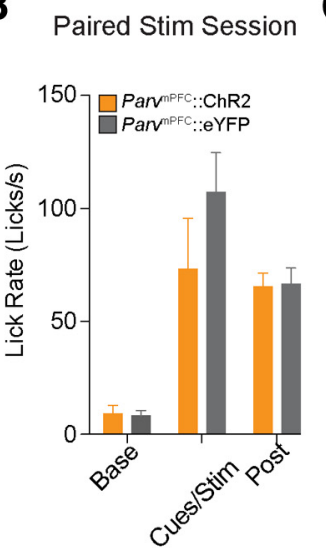

D

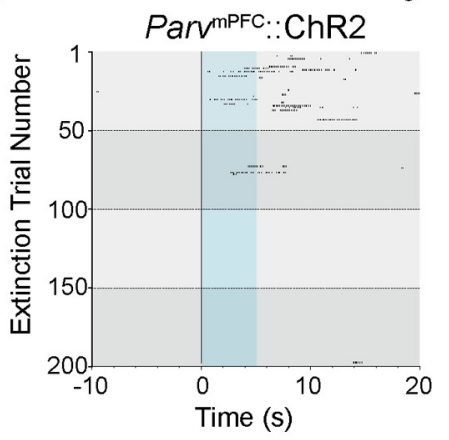

E
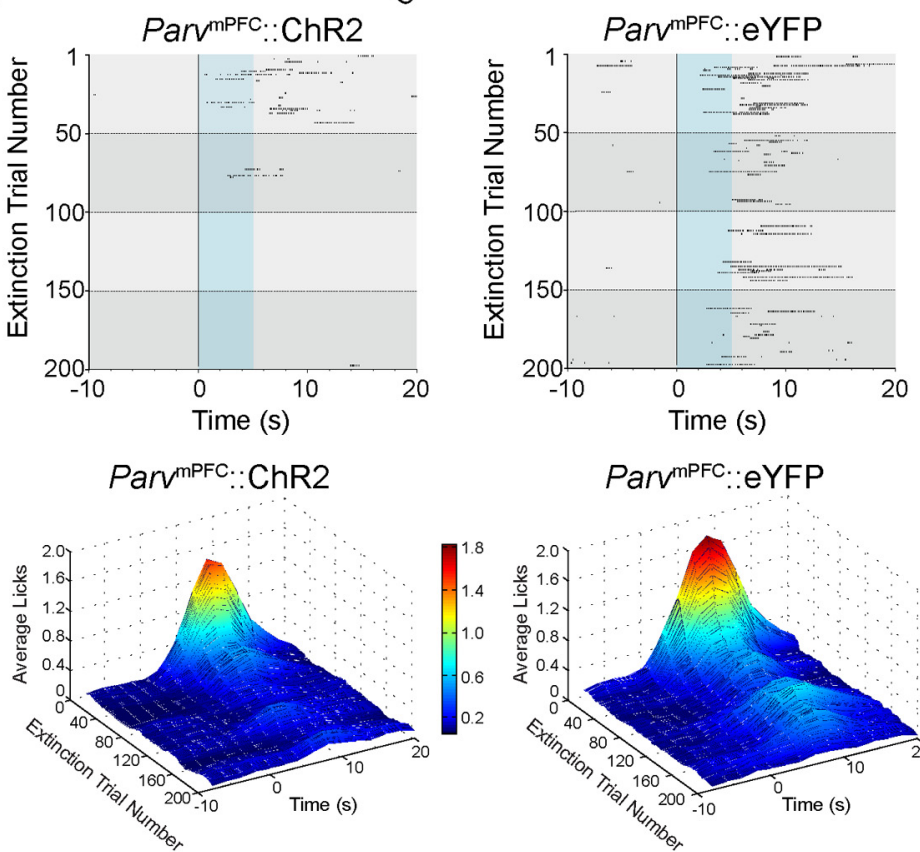

ParvmPFc.:eYFP

$\mathbf{F}$

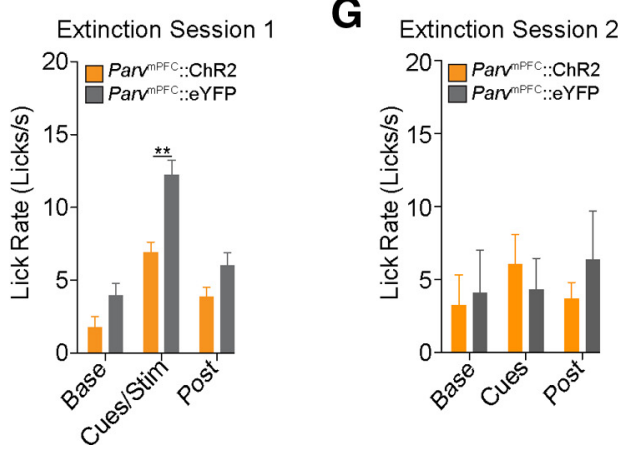

Figure 3. Photostimulation of $\mathrm{PV}+$ interneurons within the $\mathrm{mPFC}$ during $\mathrm{CS}$ presentation facilitates extinction of cue-reward

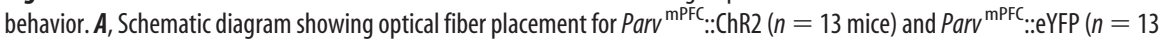
mice) in the $\mathrm{mPFC}$ on corresponding coronal brain atlas plates. D, Dorsal; $V$, ventral; $M$, medial; L, lateral. $\boldsymbol{B}$, Average lick rates

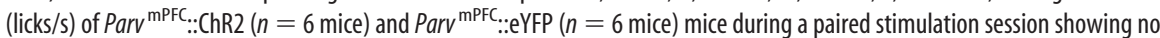
significant differences in licking behavior in response to optical activation of PV neurons or control stimulation. "Base" refers to the 10 s interval before CS delivery, "cues/stim" refers to the 10 s interval starting at CS onset, and "post" refers to the 10 sinterval starting at the end of the cue/stim period. C, Average lick rates (lick/s) of Parv ${ }^{\mathrm{mPFC}}$.:ChR2 ( $n=5$ mice) and Parv ${ }^{\mathrm{mPFC}} .: \mathrm{eYFP}(n=$ 6 mice) mice during an unpaired stimulation session showing no difference in licking behavior in response to Pavlovian cues in both groups. "Base" refers to the $10 \mathrm{~s}$ interval before optical stimulation. "Cues" refers to the 10 s interval starting at CS onset. "Post" refers to a 10 s interval starting at the end of the 10 s interval starting at the end of the of the $C S$ onset interval. D, Representative

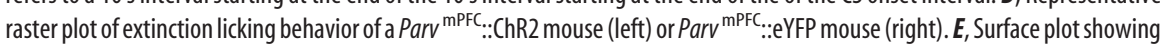
the average lick data during the first extinction session (200 CS deliveries without sucrose delivery) between the Parv ${ }^{\mathrm{mPFC} .: \text {.:ChR2 }}$ group ( $n=13$ mice; left) and the Parv ${ }^{\mathrm{MPFC}}$ ::eYFP group ( $n=13$ mice; right). $\boldsymbol{F}$, Average lick rates (licks/s) during the first

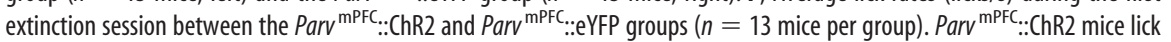

reward-seeking behavior (licking) faster than the Parv ${ }^{\mathrm{mPFC}}:$ :eYFP mice $(n=13)$ (Fig. 3D-F). When compared across the entire extinction session (200 CS presentations and concurrent optical stimulation without sucrose delivery), Parv ${ }^{\mathrm{mPFC}}$ :: ChR2 mice displayed significantly less licking behavior than Parv ${ }^{\text {PFC }_{\text {::eYFP }}}$ mice during the cue period (repeatedmeasures ANOVA group vs time interaction $F_{(2,48)}=4.734, p=0.013$, independent $t$ test during cue period: $t_{24}=-4.313 ; p<$ 0.001 ; Fig. $3 F)$. A subset of Parv ${ }^{\mathrm{mPFC}}:: \mathrm{ChR} 2$ and Parv ${ }^{\text {mPFC }:: e Y F P ~ m i c e ~}(n=7$ mice per group) were run in a subsequent extinction session (200 CS presentations without sucrose delivery) to determine whether photostimulation of mPFC PV + FSIs on extinction day 1 could alter a longer term extinction. In this second extinction session, neither group received photostimulation. When compared across the first 50 trials, no difference was observed in licking behavior during the cue period between the Parv ${ }^{\mathrm{mPFC}}:: \mathrm{ChR} 2$ and

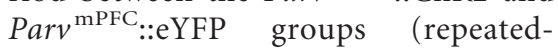
measures ANOVA group vs time interaction $F_{(1,12)}=0.341, p=0.570$, independent $t$ test during cue period: $t_{12}=0.671, p=0.515$; Fig. $3 G$ ). Together, these data suggest that circuitmediated inhibition of the mPFC through selective activation of $\mathrm{PV}+$ FSIs during cue processing can facilitate acutely the extinction of highly salient learned cue-reward associations.

\section{Discussion}

Responding to environmental changes and inhibiting maladaptive actions are fundamental components of behavioral flexibility. The mPFC has been identified as a critical circuit node involved in modulating the expression and extinction of cue-mediated behaviors (Kalivas et al., 2006; Quirk and Mueller, 2008; Peters et al., 2009; Sotres-Bayon and Quirk, 2010; Van den Oever et al., 2010). Here, we used optogenetic strategies to identify, record, and manipulate PV FSIs within the mPFC. Recent evidence suggests that mPFC PV + FSIs fire in millisecond synchrony and can modulate decision making in reward-related behaviors (Kvitsiani et al., 2013). However, the functional dy-

significantly less during the cues/stim period compared with

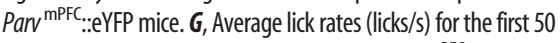
trials during the second extinction session for Parv ${ }^{\text {PPCC...ChR2 and }}$

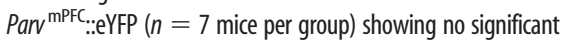
difference in licking between both groups during the cue period. ${ }^{*} p<0.05$; ${ }^{* *} p<0.01$. 
namics of intra-mPFC PV+ FSI signaling remain elusive. Here, we show that selective activation of PV + FSIs results in a transient global inhibition of PrL network activity that can accelerate the extinction of a well learned cue-reward association. Therefore, activity of PV + FSIs may act to facilitate the transition from a cue-driven to flexible behavioral state. This is not due to alterations in reward-consumption because this was unaffected by mPFC PV + FSI photostimulation. Many neuropsychiatric disorders partially manifest as habitually expressed behavioral responses to salient stimuli and are frequently treated by exposure therapy to extinguish cue-behavior associations. Our findings suggest that the extinction process may be aided, at least in part, by the selective manipulation of a specific mPFC interneuron subtype during exposure to the motivating stimuli. Although these results demonstrate the functional significance of PV+ neurons during extinction, future studies are required to determine whether the precise timing of $\mathrm{PV}+$ neuronal activation (e.g., explicit activated paired or unpaired to the CS) is necessary for facilitated extinction learning.

Learned associations that influence behavior correlate with changes in patterned neural activity within mPFC networks (Dalley et al., 2004; Peters et al., 2009). Aversive conditioning increases PrL neuronal firing during cue presentation (BurgosRobles et al., 2009). Appetitive behaviors such as drug-seeking are altered by changes in PrL and IL neural activity, with pharmacological inactivation of the PrL and IL affecting drug-seeking and extinction behaviors, respectively (LaLumiere and Kalivas, 2008; Ovari and Leri, 2008; Peters et al., 2008; Rogers et al., 2008). The present findings complement these studies, but also identify mPFC PV+ FSIs as critical circuit subnodes that act to suppress cortical activity to influence the processing of emotionally salient cues that drive behaviors. Although our data strongly suggest that our manipulations preferentially targeted the PrL over other areas of the MPFC, we cannot rule out that activation of PV + FSIs in the IL or ACC did not contribute to our behavioral findings.

Cortical PV + FSIs orchestrate cortical oscillations, maintain cortical network activity, and mediate cognitive behaviors (Cardin et al., 2009; Sohal et al., 2009; Uhlhaas and Singer, 2010; Isaacson and Scanziani, 2011; Yizhar et al., 2011). Highfrequency constant stimulation of $\mathrm{PV}+$ neurons was found recently to disrupt the acquisition and performance of a delayed alternation task in mice (Rossi et al., 2012). The present findings and previous results complement previous neuroanatomical tracing investigations of afferent and efferent projections of the mPFC. Both PrL and IL mPFC subregions exhibit dense interconnectivity with subcortical emotion processing centers, including the ventral tegmental area, nucleus accumbens, and basolateral amygdala. Therefore, mPFC output neurons can modulate directly the activity and subsequent behavioral responses controlled by these regions (Vertes, 2004; Gabbott et al., 2005; Gutman et al., 2012). Here, we found that our manipulations activated the PrL division of the mPFC preferentially. The observed accelerated extinction of a cue-reward behavior via selective stimulation of PrL FSIs is consistent with the hypothesized differential roles played by the PrL and IL subregions during the expression and extinction of cue-mediated behaviors (Milad and Quirk, 2002; Burgos-Robles et al., 2009). Intriguingly, a study used in vivo optogenetics and electrophysiology to investigate mPFC circuit function and found that activating IL pyramidal cells led to an inhibition of PrL output, highlighting a possible microcircuit mechanism for IL-mediated extinction (Ji and Neugebauer, 2012). In conclusion, we identify here a new role for
FSI-mediated cortical inhibition in modulating cue-mediated behaviors. Future studies are needed to further disentangle the precise function of selective PrL and IL circuits because precise regulation of cortical network activity may have therapeutic benefit in the treatment of a variety of neuropsychiatric disorders.

\section{References}

Burgos-Robles A, Vidal-Gonzalez I, Quirk GJ (2009) Sustained conditioned responses in prelimbic prefrontal neurons are correlated with fear expression and extinction failure. J Neurosci 29:8474-8482. CrossRef Medline

Cardin JA, Carlén M, Meletis K, Knoblich U, Zhang F, Deisseroth K, Tsai LH, Moore CI (2009) Driving fast-spiking cells induces gamma rhythm and controls sensory responses. Nature 459:663-667. CrossRef Medline

Courtin J, Chaudun F, Rozeske RR, Karalis N, Gonzalez-Campo C, Wurtz H, Abdi A, Baufreton J, Bienvenu TC, Herry C (2014) Prefrontal parvalbumin interneurons shape neuronal activity to drive fear expression. Nature 505:92-96. CrossRef Medline

Dalley JW, Cardinal RN, Robbins TW (2004) Prefrontal executive and cognitive functions in rodents: neural and neurochemical substrates. Neurosci Biobehav Rev 28:771-784. CrossRef Medline

Freund TF (2003) Interneuron Diversity series: Rhythm and mood in perisomatic inhibition. Trends Neurosci 26:489-495. CrossRef Medline

Gabbott PL, Warner TA, Jays PR, Salway P, Busby SJ (2005) Prefrontal cortex in the rat: projections to subcortical autonomic, motor, and limbic centers. J Comp Neurol 492:145-177. CrossRef Medline

Gutman DA, Keifer OP Jr, Magnuson ME, Choi DC, Majeed W, Keilholz S, Ressler KJ (2012) A DTI tractography analysis of infralimbic and prelimbic connectivity in the mouse using high-throughput MRI. Neuroimage 63:800-811. CrossRef Medline

Hayton SJ, Olmstead MC, Dumont ÉC (2011) Shift in the intrinsic excitability of medial prefrontal cortex neurons following training in impulse control and cued-responding tasks. PLoS One 6:e23885. CrossRef Medline

Isaacson JS, Scanziani M (2011) How inhibition shapes cortical activity. Neuron 72:231-243. CrossRef Medline

Jennings JH, Sparta DR, Stamatakis AM, Ung RL, Pleil KE, Kash TL, Stuber GD (2013) Distinct extended amygdala circuits for divergent motivational states. Nature 496:224-228. CrossRef Medline

Ji G, Neugebauer V (2012) Modulation of medial prefrontal cortical activity using in vivo recordings and optogenetics. Mol Brain 5:36. CrossRef Medline

Kalivas PW, Peters J, Knackstedt L (2006) Animal models and brain circuits in drug addiction. Mol Interv 6:339-344. CrossRef Medline

Kvitsiani D, Ranade S, Hangya B, Taniguchi H, Huang JZ, Kepecs A (2013) Distinct behavioural and network correlates of two interneuron types in prefrontal cortex. Nature 498:363-366. CrossRef Medline

LaLumiere RT, Kalivas PW (2008) Glutamate release in the nucleus accumbens core is necessary for heroin seeking. J Neurosci 28:3170-3177. CrossRef Medline

Marín O (2012) Interneuron dysfunction in psychiatric disorders. Nat Rev Neurosci 13:107-120. CrossRef Medline

Markram H, Toledo-Rodriguez M, Wang Y, Gupta A, Silberberg G, Wu C (2004) Interneurons of the neocortical inhibitory system. Nat Rev Neurosci 5:793-807. CrossRef Medline

Milad MR, Quirk GJ (2002) Neurons in medial prefrontal cortex signal memory for fear extinction. Nature 420:70-74. CrossRef Medline

Ovari J, Leri F (2008) Inactivation of the ventromedial prefrontal cortex mimics re-emergence of heroin seeking caused by heroin reconditioning. Neurosci Lett 444:52-55. CrossRef Medline

Peters J, LaLumiere RT, Kalivas PW (2008) Infralimbic prefrontal cortex is responsible for inhibiting cocaine seeking in extinguished rats. J Neurosci 28:6046-6053. CrossRef Medline

Peters J, Kalivas PW, Quirk GJ (2009) Extinction circuits for fear and addiction overlap in prefrontal cortex. Learn Mem 16:279-288. CrossRef Medline

Quirk GJ, Mueller D (2008) Neural mechanisms of extinction learning and retrieval. Neuropsychopharmacology 33:56-72. CrossRef Medline

Rogers JL, Ghee S, See RE (2008) The neural circuitry underlying reinstate- 
ment of heroin-seeking behavior in an animal model of relapse. Neuroscience 151:579-588. CrossRef Medline

Rossi MA, Hayrapetyan VY, Maimon B, Mak K, Je HS, Yin HH (2012) Prefrontal cortical mechanisms underlying delayed alternation in mice. J Neurophysiol 108:1211-1222. CrossRef Medline

Santini E, Quirk GJ, Porter JT (2008) Fear conditioning and extinction differentially modify the intrinsic excitability of infralimbic neurons. J Neurosci 28:4028-4036. CrossRef Medline

Sohal VS, Zhang F, Yizhar O, Deisseroth K (2009) Parvalbumin neurons and gamma rhythms enhance cortical circuit performance. Nature 459: 698-702. CrossRef Medline

Sotres-Bayon F, Quirk GJ (2010) Prefrontal control of fear: more than just extinction. Curr Opin Neurobiol 20:231-235. CrossRef Medline

Sparta DR, Stamatakis AM, Phillips JL, Hovelsø N, van Zessen R, Stuber GD (2012) Construction of implantable optical fibers for long-term optogenetic manipulation of neural circuits. Nat Protoc 7:12-23. CrossRef Medline

Stamatakis AM, Stuber GD (2012) Activation of lateral habenula inputs to the ventral midbrain promotes behavioral avoidance. Nat Neurosci 15:11051107. CrossRef Medline

Tsai HC, Zhang F, Adamantidis A, Stuber GD, Bonci A, de Lecea L, Deisseroth K (2009) Phasic firing in dopaminergic neurons is sufficient for behavioral conditioning. Science 324:1080-1084. CrossRef Medline

Uhlhaas PJ, Singer W (2010) Abnormal neural oscillations and synchrony in schizophrenia. Nat Rev Neurosci 11:100-113. CrossRef Medline
Van den Oever MC, Spijker S, Smit AB, De Vries TJ (2010) Prefrontal cortex plasticity mechanisms in drug seeking and relapse. Neurosci Biobehav Rev 35:276-284. CrossRef Medline

Van den Oever MC, Rotaru DC, Heinsbroek JA, Gouwenberg Y, Deisseroth K, Stuber GD, Mansvelder HD, Smit AB (2013) Ventromedial prefrontal cortex pyramidal cells have a temporal dynamic role in recall and extinction of cocaine-associated memory. J Neurosci 33:18225-18233. CrossRef Medline

Van De Werd HJ, Rajkowska G, Evers P, Uylings HB (2010) Cytoarchitectonic and chemoarchitectonic characterization of the prefrontal cortical areas in the mouse. Brain Struct Funct 214:339-353. CrossRef Medline

van Zessen R, Phillips JL, Budygin EA, Stuber GD (2012) Activation of VTA GABA Neurons Disrupts Reward Consumption. Neuron 73:1184-1194. CrossRef Medline

Vertes RP (2004) Differential projections of the infralimbic and prelimbic cortex in the rat. Synapse 51:32-58. CrossRef Medline

Vogels TP, Abbott LF (2009) Gating multiple signals through detailed balance of excitation and inhibition in spiking networks. Nat Neurosci 12: 483-491. CrossRef Medline

Yizhar O, Fenno LE, Prigge M, Schneider F, Davidson TJ, O'Shea DJ, Sohal VS, Goshen I, Finkelstein J, Paz JT, Stehfest K, Fudim R, Ramakrishnan C, Huguenard JR, Hegemann P, Deisseroth K (2011) Neocortical excitation/inhibition balance in information processing and social dysfunction. Nature 477:171-178. CrossRef Medline 